\title{
InCLUSÃo DE ALUNOS COM SÍNDROME DE DOWN: DISCURSOS DOS PROFESSORES $\star$
}

\author{
Lisiane Machado de Oliveira-Menegotto $\star \star$ \\ Fernanda de Oliveira Martini ${ }^{\star \star \star}$ \\ Laura Kolberg Lipp ${ }^{\star \star \star \star}$
}

\begin{abstract}
Resumo
O artigo pretende discutir os discursos de professores da cidade de Novo Hamburgo/RS sobre a inclusão de alunos com sindrome de Down. Foi realizada uma pesquisa qualitativa, de caráter exploratório, contando com a participação de 19 professores de alunos com síndrome de Down de escolas regulares de Novo Hamburgo/RS. Eles foram entrevistados e seus discursos foram analisados a partir de análise de conteúdo qualitativa. Os resultados indicam que eles manifestaram sentimentos de desamparo, impotência e incompetência frente à inclusão, sobretudo, em decorrência da carência de espaços de discussão e formação sobre o assunto, apontando para possibilidades de intervenção da Psicologia.
\end{abstract}

Palavras-chave: sindrome de Down; educação inclusiva; professor.

INCLUSION OF STUDENTS WITH DOWN SYNDROME:

TEACHERS' SPEECH

\begin{abstract}
This study wishes to examine the discourses of teachers from Novo Hamburgo city, Brazil, about the inclusive education of students with Down syndrome. This is a qualitative exploratory study and it had a participation of 19 teachers of students with Down syndrome in regular schools in Novo Hamburgo city, Brazil. They were interviewed and their discourses were analyzed according to the qualitative content analysis. The results indicate that they expressed feelings of helplessness, impotence and incompetence in dealing with inclusive education, particularly because of the scarcity of opportunities to study and discuss about it, pointing to possibilities of Psychology intervention.

Keywords: Down syndrome; inclusive education; teacher

$\star$ Pesquisa que contou com o apoio da Feevale

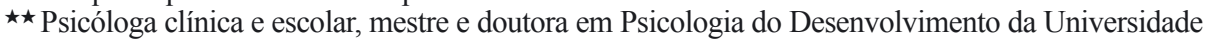
Federal do Rio Grande do Sul, docente do curso de Psicologia e pesquisadora da Feevale - Novo Hamburgo/RS. Endereço: Universidade Feevale. RS 239, 2755. Vila Nova. CEP: 93352-000 Novo Hamburgo, RS - Brasil.

E-mail: lisianeoliveira@feevale.br

$\star \star \star$ Psicóloga formada pela Feevale e voluntária no Programa de Aperfeiçoamento Científico da Feevale. E-mail: femartini@brturbo.com.br

$\star \star \star \star$ Psicóloga formada pela Feevale. Foi bolsista de iniciação científica da FAPERGS.

E-mail: lauralipp@gmail.com
\end{abstract}


O paradigma da exclusão é milenar dentro da história da humanidade. Ainda no início do século XX, o surgimento de escolas especiais e centros de habilitação e reabilitação legitimou a exclusão, mantendo as pessoas consideradas diferentes afastadas do convívio social. Foi somente no final da década de 60 que surgiram movimentos para inserir pessoas com deficiências na educação, esporte e lazer tentando romper uma idéia de segmentação (SAAD, 2003).

Ainda que as escolas especiais sejam, historicamente, um lugar de segregação, Beyer (2005) salienta a importância de seu surgimento, uma vez que antes disso, não havia lugar para as crianças com necessidades educacionais especiais em nenhum espaço escolar. Nesse sentido, com o advento da escola especial, as crianças com necessidades educacionais especiais passaram a ter um lugar de direito na escola, mesmo que esse fosse segregado do restante das crianças. Isso possibilitou a saída de muitas crianças da clausura do lar, e conseqüentemente mais oportunidades de laços com o social.

Inicialmente, a inserção das pessoas com deficiência nos vários segmentos da sociedade ocorria a partir da perspectiva de integração, cujo princípio é o da reabilitação, para que a pessoa possa participar da sociedade. Nesse sentido, o indivíduo deveria ser preparado para se adaptar ao convívio social geral e retirado desse convívio caso não houvesse adequação. Foi na década de 80 que se iniciou o movimento da inclusão, liderado por intelectuais, organização de pessoas com deficiência e simpatizantes da causa, uma vez que a experiência da integração mostrava-se insuficiente, além da discriminação ainda vigente (SAAD, 2003). Mas somente a partir de 1994 que o movimento da educação inclusiva eclode no cenário mundial, em função da Conferência Mundial da UNESCO sobre Necessidades Educacionais Especiais, momento em que se discutiu a educação como sendo uma questão de direitos humanos. A partir de então, houve a necessidade de se redimensionar a escola e a educação como um todo para que todos os indivíduos com algum tipo de deficiência pudessem ser parte integrante das escolas (KARAGIANNIS; STAINBACK, W.; STAINBACK, S., 1999). Foi nessa conferência que a Declaração de Salamanca (UNESCO, 1994) foi elaborada, tornando-se um documento de referência na discussão sobre diretrizes básicas para a formulação e reforma de políticas e sistemas educacionais de acordo com o movimento de inclusão social.

Em 1999, foi celebrado um documento em Guatemala, numa convenção interamericana que buscava eliminar todas as formas de discriminação contra pessoas portadoras de qualquer deficiência. O Brasil é signatário deste documento, que foi aprovado pelo Congresso Nacional, através do Decreto Legislativo $\mathrm{n}^{\mathrm{o}} 198$, de 13 de junho de 2001, e promulgado pelo Decreto $\mathrm{n}^{\mathrm{o}} 3.956$, de 08 de outubro de 2001, da Presidência da República. No mesmo ano, foi aprovada a Carta para o Terceiro Milênio, em Londres, que visa à proteção dos direitos das pessoas com deficiência mediante o apoio pleno a inclusão. Em 2001, foi aprovada a Declaração Internacional de Montreal sobre Inclusão, visando identificar e implementar recursos acessíveis, sustentáveis e seguros que garantam o acesso igualitário a todos os espaços da vida. 
No Brasil, o movimento também teve o seu início por volta dos anos 90, sendo amparado pela Constituição Federal de 1988 e pela Lei de Diretrizes e Bases da Educação Nacional n. 9.394/96, as quais estabelecem que a educação é direito de todos e que as pessoas com necessidades educacionais especiais devem ter atendimento educacional preferencialmente na rede regular de ensino, que deverá garantir atendimento educacional especializado aos portadores de deficiência. Embora a legislação ampare a concepção inclusiva da educação, não define obrigatoriedade e até admite a possibilidade de escolarização que não seja na escola regular (MENDES, 2006).

Além dos documentos e leis supracitados, há outros movimentos coletivos liderados principalmente pelos pais de pessoas com deficiência, tais como, associações de pais e familiares de pessoas com deficiências, que buscam amparo legal para combater a discriminação e, sobretudo, defender a inclusão. Muito embora a inclusão esteja assegurada em uma legislação específica, sabemos que ela não se efetiva por decreto. A inclusão escolar se faz possível a partir de ações e políticas educacionais, além da disposição dos professores em celebrar a diferença. Ademais, precisamos ter em mente que há um estigma e preconceito que fazem parte de nossa cultura e que tem reforçado o paradigma da exclusão, como já dizia Mrech (2001). Nesse sentido, é necessário que se trabalhe os diversos segmentos da sociedade (família, escola, trabalho, lazer) para que se fale em inclusão como um todo, pois é a própria sociedade que se constitui como maior fonte de exclusão.

Outra discussão que se faz necessária é sobre a concepção a respeito da inclusão escolar. Dentre várias concepções vigentes, infelizmente, não é raro a inclusão escolar ser apreendida como um mero cumprimento da legislação, no sentido de aceitar a criança com necessidades educacionais especiais. Esta concepção na prática, no entanto, é insuficiente, uma vez que não basta abrir os portões das escolas e apenas inserir a criança com necessidades educacionais especiais em classes regulares, sem o devido preparo e amparo das pessoas que vão lidar com ela. Nesse sentido, os professores acabam sendo forçados a assumir alunos com necessidades educacionais especiais, sem que estejam preparados e capacitados e as conseqüências disso podem ser desastrosas.

A educação inclusiva implica mudanças de paradigmas. É necessário pensarmos que todos os alunos são diferentes e não somente aqueles que apresentam algum tipo de deficiência. Sendo assim, é preciso que se pense a educação de uma forma que contemple cada criança, de acordo com suas capacidades (BEYER, 2005). As adaptações curriculares, que ocorrem conforme as possibilidades de aprendizagem de cada aluno, podem garantir o respeito às diferenças, abandonando um ideal de aprendizagem calcado na premissa da homogeneidade. Nessa perspectiva, o estudo de Holden e Stewart (2002) aponta para a importância de a escola realizar adaptações curriculares, oferecendo, sempre que necessário, um currículo apropriado para todos e não somente para os alunos com síndrome de Down. Nesse sentido, a educação inclusiva requer modificações pedagógicas nas escolas, para que se possa garantir às crianças uma melhor escolarização, considerando suas capacidades e potencialidades individuais. 
No que se refere a ações e políticas educacionais em relação à prática docente, tanto a Constituição Federal, como a Lei de Diretrizes e Bases da Educação Nacional $n^{\circ} 9.394 / 96$ estabelecem que os professores devem estar qualificados para o atendimento especializado a pessoas com necessidades educacionais especiais. A lei, portanto, assegura a importância da qualificação dos docentes, mas na prática essa questão ainda está muito incipiente.

O maior desafio, apontado por Saad (2003), é que a escola, diante da determinação legal para receber alunos com necessidades educacionais especiais, não está preparada em termos de recursos humanos e infra-estrutura. Em geral, os professores não estão capacitados para lidar com as diferenças. Podem ficar em pânico, diante de um aluno com necessidades educacionais especiais, ou simplesmente tolerá-lo, desde que ele permaneça em sala de aula como um mero figurante. Em função disso, Voivodic (2007) refere a importância de implementar ações de apoio e mediação para que a inclusão seja efetivada. Afinal, estamos, de um lado, diante da obrigatoriedade das escolas receberem os alunos que, até então, eram encaminhados para as classes e escolas especiais, e de outro estamos frente à falta de preparo e capacitação dos professores para lidar com a inclusão de crianças com deficiência em suas classes. Nesse sentido, trabalhar com o professor é fundamental para que possamos, efetivamente, falar de educação inclusiva.

Os resultados da pesquisa sobre inclusão de alunos com síndrome de Down em escolas de ensino regular, realizada por Voivodic (2007), revelam que as escolas têm dificuldade de conduzir o processo de inclusão, mostrando-se bastante desorientadas em relação a isso. A proposta de inclusão das escolas ainda é frágil e receber crianças com deficiência sem um apoio externo adequado parece revelar ainda mais a sua vulnerabilidade.

Inclusão não é apenas colocar crianças com deficiência no ensino regular sem que haja um suporte aos professores (MRECH, 1999). Já mencionamos a importância do trabalho com os professores, entretanto não podemos esquecer que a inclusão não deve ser somente uma proposta do professor, mas também da escola como um todo. Concordamos com Mantoan (2000), que refere que a inclusão não é possível através de modelos tradicionais de organização do sistema escolar. Nesse sentido, é necessário que a escola seja repensada, redimensionada, considerando os aspectos pedagógicos, psicológicos, sociais, entre outros.

A importância da formação de professores é referida em estudos como o de Mukherjee, Lighfoot e Sloper (2000) e Michels (2006) que ressaltam o trabalho com os professores no contexto da inclusão de alunos com doenças crônicas. Gilmore, Campbell e Cuskelly (2003a) apontam para lacunas nas formações de professores, o que também é enfatizado por Mrech (2001), que refere que o professor de ensino regular não aprendeu a lidar com os alunos diferentes ou deficientes. Nesse sentido, rever a formação dos cursos de magistério, bem como das licenciaturas parece ser fundamental. Gilmore, Campbell e Cuskelly (2003b) apontaram também para a importância de um trabalho com os professores que estão realizando cursos de graduação, como por exemplo, Pedagogia. 
De acordo com os resultados de sua pesquisa, os professores modificaram sua percepção em relação aos alunos com deficiência, após conhecer mais sobre a defasagem em questão e discutir casos.

Muitas vezes, as escolas e, sobretudo, os professores têm uma idéia de que necessitam de palestras para conhecer mais sobre as síndromes e demais dificuldades e defasagens que acometem seus alunos com Necessidades Educacionais Especiais. No entanto, o estudo de Gilmore, Campbell e Cuskelly (2003a) revelou que as informações não são suficientes. Isso porque, apesar de os professores e demais pessoas da comunidade terem conhecimento suficiente sobre a síndrome, a maioria não acredita na inclusão de tais alunos em classes do ensino regular.

O maior impasse para a inclusão de alunos com necessidades educacionais especiais parece ser a crença de que todos os alunos devem se adaptar aos parâmetros de normalidade, enquadrando-se àquilo que é esperado para determinada série, currículo e faixa etária. Trata-se da concepção da integração do aluno na escola que, segundo Sanches e Teodoro (2006), exige que alunos com necessidades educacionais especiais e os professores que os acompanham se adaptem às regras e ao funcionamento do sistema regular, para ter direito a um lugar no meio escolar regular, enquanto que o sistema não se questiona nem preconiza a mudança.

Diferente dessa concepção, a educação inclusiva trabalha com as possibilidades de cada aluno, esperando que cada um atinja o máximo de suas possibilidades (MRECH, 2001). Trata-se de um trabalho com enfoque na singularidade de cada aluno, o que requer um olhar que vá além das metodologias pedagógicas. A escola inclusiva também deve estar preparada para se adaptar ao aluno, uma vez que cada criança é única e necessita diferentes estímulos e adaptações curriculares para uma melhor escolarização, conforme proposto no estudo de Holden e Stewart (2002). Sendo assim, quando falamos de educação inclusiva, salientamos a importância de o professor olhar para o aluno como alguém capaz de transformar, o que é possível quando ele desloca o olhar da patologia para a diferença (FABRÍCIO; SOUZA; ZIMMERMANN, 2007).

Numa perspectiva de investigação semelhante ao presente estudo, Aragão et al. (2004) realizaram estudos com o objetivo de investigar a concepção de professores, coordenadores pedagógicos e diretores sobre inclusão escolar. Os resultados evidenciaram que a concepção de inclusão dos participantes ainda é, em sua maioria, de socialização. Também ficou evidente a necessidade de um acompanhamento constante do trabalho do professor, não se restringindo a cursos ou capacitações isolados. Os professores ainda mencionaram a importância de um trabalho coletivo, levando-se em consideração professores e funcionários, para que a inclusão se efetue. Outros estudos que salientaram a importância da capacitação dos docentes foram os de Almeida-Verdu, Fernandes e Rodrigues (2002) e Silva e Aranha (2005).

Além da importância de se trabalhar com o professor, o estudo de Hanson et al. (2001) apontou a família e a sociedade como fatores fundamentais que influenciam o processo de inclusão. Também assinalou a importância de se ter uma articulação entre a escola e os terapeutas que trabalham com os alunos com 
necessidades educacionais especiais. Nessa mesma perspectiva, Beyer (2005) refere que uma escola aberta exige que os alunos, as famílias, os professores e as equipes diretivas e pedagógicas, os funcionários e gestores do projeto político-pedagógico se impliquem no processo de uma forma integrada. Do ponto de vista da família, é importante assinalar que é neste contexto que ocorre a primeira inclusão, através da constituição do laço de filiação, que se dá pelo reconhecimento do filho como pertencente à família. O nascimento de um filho com deficiência captura os pais nas impossibilidades impostas pelo diagnóstico médico, precipitando uma insuficiência no filho, que inevitavelmente terá repercussões (OLIVEIRA-MENEGOTTO, 2006).

Como podemos perceber, os estudos evidenciam o professor como peçachave na prática da educação inclusiva, enfocando a importância do apoio ao professor e de um trabalho articulado entre escola e família. O presente artigo teve como objetivo discutir os discursos de professores de escolas da cidade de Novo Hamburgo/RS sobre a inclusão de alunos com síndrome de Down. Optamos por trabalhar com a inclusão de alunos com síndrome de Down, por ser a alteração genética de maior ocorrência no mundo. Ademais, de acordo com a Secretaria de Educação Especial do Ministério da Educação (BRASIL, 2006), a síndrome de Down é classificada como condutas típicas, sendo consideradas como necessidades especiais. Dentre inúmeras características, que são facilmente identificadas, por conta das alterações físicas específicas, as pessoas com síndrome de Down apresentam deficiência mental e uma defasagem no desenvolvimento neuropsicomotor (VOIVODIC, 2007).

\section{MÉTODO:}

\section{Participantes}

Participaram do estudo 19 professores, sendo 18 mulheres e um homem, entre 19 e 45 anos que trabalham com alunos com síndrome de Down em escolas públicas e privadas do município de Novo Hamburgo/RS. No que se refere à escolaridade, um professor apresenta apenas o curso de magistério em nível médio (5\%), cinco professores apresentam ensino superior incompleto (26\%) e 13 professores apresentam ensino superior completo (69\%).

Em relação ao início do curso de magistério em nível médio, dois professores $(11 \%)$ iniciaram o curso na década de 70 , oito professores $(42 \%)$ na década de 80, seis professores na década de 90 e, por fim, um professor iniciou o curso após o ano 2000 . No que se refere à conclusão do curso de magistério, sete professores (37\%) finalizaram o curso na década de 80 , sete professores na década de 90 e três professores concluíram o curso após o ano 2000. Dois professores não cursaram o curso de magistério em nível médio.

Em termos do início do curso superior, quatro professores $(21 \%)$ iniciaram na década de 80 , nove professores (48\%) na década de 90 e quatro professores iniciaram o curso de graduação após o ano 2000. Em se tratando da conclusão do curso superior, dois professores (11\%) concluíram na década de 80 , quatro pro- 
fessores $(21 \%)$ na década de 90 e seis professores finalizaram seu curso superior após o ano 2000. Cinco professores (26\%) ainda não concluíram o curso superior, um professor (5\%) não referiu a data de início e término e um professor (5\%) não está fazendo curso superior.

\section{Delineamento e Procedimentos}

Foi realizada uma pesquisa qualitativa de cunho exploratório. Inicialmente, entramos em contato com todas as escolas regulares de ensino fundamental do município de Novo Hamburgo/RS para mapear as escolas onde os alunos com síndrome de Down estavam matriculados. Do total de 86 escolas de ensino fundamental de Novo Hamburgo, somente 17 escolas (19,76\%) tinham alunos com síndrome de Down matriculados no ensino fundamental. Das 17 escolas, cinco optaram por não participar, restando 12 escolas, sendo uma escola estadual, três escolas privadas e oito escolas municipais. Após o contato com as escolas, os professores que trabalham com os alunos com síndrome de Down foram convidados a participar da pesquisa. Os professores foram entrevistados individualmente nas escolas em que trabalham. Foi solicitado que a entrevista ocorresse em um local privado, sem a participação de outras pessoas da instituição. A entrevista foi precedida pela explicação dos objetivos da pesquisa, leitura e assinatura do Termo de Consentimento Livre e Esclarecido. Todas as entrevistas foram gravadas e, posteriormente, transcritas literalmente.

\section{INSTRUMENTOS}

Foi realizada uma entrevista, a partir de um roteiro semi-estruturado, abordando questões, como: formação acadêmica do professor, percepção sobre o seu trabalho de inclusão, percepção sobre a escola, diante da inclusão, percepção sobre os pais dos alunos com síndrome de Down, percepção dos pais dos demais alunos, percepção sobre os demais professores, entre outras.

\section{Análise dos Dados}

A presente pesquisa utilizou-se da análise qualitativa de conteúdo, seguindo a estratégia de análise e interpretação de Laville e Dionne (1999), a partir da construção iterativa de uma explicação. Tal estratégia requer explicações lógicas do objeto estudado, examinando as unidades de sentido, as suas inter-relações e as categorias que elas se encontram reunidas. Para tanto, num primeiro momento, foram realizadas sucessivas leituras do material transcrito, transformando-o em categorias temáticas. Posteriormente, realizamos uma articulação com a literatura pesquisada. As categorias temáticas, construídas a partir das respostas das entrevistas, são as seguintes: Formação acadêmica x discussão da inclusão; Percepção sobre o seu trabalho de inclusão; Concepção de inclusão do professor; Percepção em relação à escola diante da inclusão; Percepção sobre os demais professores da escola; Percepção sobre os pais dos alunos com síndrome de Down; Percepção sobre os pais dos colegas dos alunos com síndrome de Down. 


\section{Resultados e Discussão}

\section{Formação acadêmica $x$ discussão da inclusão:}

Os professores mencionaram que a temática da inclusão raramente foi abordada em sala de aula, tanto no magistério em nível médio como no curso de graduação. É importante salientar que as discussões sobre inclusão se dão, no âmbito escolar e acadêmico, sobretudo, a partir da década de 90. Os professores, portanto, referem que a discussão é recente, de modo que as discussões sobre o tema partem em geral da escola em que trabalham, de cursos de extensão, especialização ou de capacitação.

O relato dos professores apresenta convergência com a história da inclusão (MENDES, 2006). Assim como a inclusão é uma prática contemporânea, as discussões sobre o tema também são recentes. O processo, historicamente, ocorreu de uma forma inversa. Inicialmente foram asseguradas leis que determinam o acesso e a permanência de todas as pessoas à escola, para depois criar espaços de discussão. Cabe também salientar a importância de a discussão sobre a inclusão ocorrer no âmbito escolar e acadêmico, permeando o currículo dos cursos de magistério e graduação, no contexto da formação de professores, não somente desde o ponto de vista da teoria, mas também da prática, na medida em que a informação por si só é insuficiente (GILMORE; CAMPBELL; CUSKELLY, 2003a).

\section{Percepção sobre o seu trabalho de inclusão:}

Os professores mencionaram que a experiência de inclusão é um desafio, cujo trabalho gera satisfações e frustrações. Alguns relataram que tiveram resistência no início, mas com o apoio da escola ficaram mais tranqüilos. Todos mencionaram a importância do apoio da escola (recursos físicos, humanos, capacitação, etc.), de discussões, cursos de aperfeiçoamento e de mais contatos com os especialistas que fazem o atendimento clínico dos alunos.

A fala dos professores remete à discussão da importância do apoio da escola para encarar o desafio. É fundamental discutirmos, primeiramente, a questão do desafio, no sentido de pensarmos o quanto a inclusão mobiliza o professor, fazendo com que ele tenha que desconstruir inúmeros paradigmas, produto de uma formação pobre em discussões e práticas no contexto da educação inclusiva. No que se refere ao apoio da escola, não podemos deixar de discutir, que o trabalho do professor em sala de aula depende do suporte da escola, em termos de proposta inclusiva, de flexibilização curricular, de adaptações nas avaliações, de turmas reduzidas, de auxílio de um outro professor (professor auxiliar), de espaços sistemáticos de discussão e capacitação, entre outros. Os professores ainda ressaltam a importância de se instituir momentos de trabalho interdisciplinar, em que professores e especialistas que trabalham clinicamente com os alunos possam discutir sobre a relação com os alunos com necessidades educacionais especiais, promovendo uma integração entre educação e saúde, de modo que um saber possa contribuir com o outro (MARTINI et al., 2007). 
A resistência inicial, mencionada pelos professores, poderia ser explicada, pelo menos parcialmente, pelo fato de que o movimento da inclusão foi liderado, segundo Saad (2003), por intelectuais, organizações de pessoas com deficiência e simpatizantes da causa, e não pela classe dos profissionais, sendo, muitas vezes sentido como uma imposição. Por isso, além de assegurar que hajam espaços de discussão sobre a inclusão, é necessário que as escolas se mobilizem para dar o apoio necessário aos profissionais, seguindo o que fora previsto nos documentos e leis sobre a inclusão no contexto escolar.

\section{Concepção de inclusão do professor:}

Os professores ressaltam que o trabalho com a inclusão requer o reconhecimento e o respeito às diferenças. Alguns professores compreendem a inclusão do ponto de vista social/escolar, no sentido de convivência social, já outros entendem a inclusão sob o aspecto da educação inclusiva, reconhecendo a indissociabilidade entre inclusão e o processo de ensino e aprendizagem. Há ainda professores que questionam a inclusão no ensino regular, mostrando o quanto os recursos humanos da escola não estão preparados (SAAD, 2003). Os professores, ao falarem sobre inclusão, salientam o quão desgastante é o trabalho.

Podemos perceber que ainda é vigente a idéia de que a escola, especialmente, para os alunos com necessidades educacionais especiais, é um espaço apenas para socialização (ARAGÃO et al., 2004). Questionar a convivência com a diferença ou apostar somente na socialização pode ser um indício de que os professores estão ainda situados no paradigma da integração (MRECH, 2001), isto é, em que o aluno deve se adaptar a um currículo, a uma proposta, a uma escola, sem considerar suas diferenças e singularidade. Por isso, que na perspectiva da integração os alunos que não conseguem se adaptar, geralmente, sofrem, podendo evadir ou ser encaminhados para uma classe especial (SANCHES; TEODORO, 2006).

A fala de um dos professores também denuncia que a diferença pode ser prejudicial, possivelmente, porque ainda há um ideal na educação de nivelamento, de homogeneidade no espaço da sala de aula. Nesse sentido, as diferenças são vistas como algo nocivo, que pode atrapalhar, ao invés de contribuir com o andamento da aula.

\section{Percepção em relação à escola diante da inclusão:}

Alguns professores mencionaram o apoio recebido pela escola, na medida em que se mostra preocupada e disponibilizando alguns espaços de discussão. Outros professores comentaram que a escola, apesar de estar evoluindo, ainda carecia de condições e recursos adequados, além de pouco apoiar os professores. Todos os professores salientaram a importância de a escola criar espaços de suporte aos professores, no sentido de possibilitar discussões, recursos físicos e humanos para dar sustentabilidade à inclusão, coadunando, assim, com o que está posto em alguns relatos de pesquisa (ALMEIDA-VERDU; FERNANDES; RODRIGUES, 2002; ARAGÃO et al., 2004; MICHELS, 2006; MUKHERJEE; LIGHFOOT; SLOPER, 2000; SILVA; ARANHA, 2005). 
A fala dos professores aponta para a importância da escola estar caminhando juntamente com o professor nesse processo, dando o suporte necessário para que a inclusão se efetive. Autores como Saad (2003) e Voivodic (2007) afirmam que a escola ainda apresenta resistências em relação à inclusão. Isso porque as escolas precisam rever os seus paradigmas sobre ensinar e aprender, sobre avaliar, sobre a concepção de sujeito, aluno, etc. O primeiro passo é rever o Projeto Político-Pedagógico, de modo a contemplar a proposta inclusiva, já que a educação inclusiva exige um redimencionamento da escola como um todo (MANTOAN, 2000). Em seguida, é fundamental que a escola possa estabelecer um espaço sistemático de discussão sobre a inclusão, de forma a envolver toda a comunidade escolar, isto é, família, funcionários, alunos e, sobretudo, professores. Como já nos diz Mrech (1999), inclusão não é somente colocar crianças deficientes no ensino regular. Sendo assim, para incluir um aluno com necessidades educacionais especiais, a escola deve oferecer um currículo apropriado para todos, considerando as diferenças (HOLDEN; STEWART, 2002).

\section{Percepção sobre os demais professores da escola:}

Os professores mencionaram que há diferentes posicionamentos de seus colegas, sendo que alguns oferecem apoio àquele que está trabalhando diretamente com o aluno com síndrome de Down, contribuindo com discussões, sugestões, opiniões. Outros evidenciam temores, resistência e preconceitos em relação ao aluno com síndrome de Down.

É importante mencionar que os resultados indicam que a inclusão ainda é motivo de resistência dentre os professores e que a escola ainda apresenta dificuldades de transformar a inclusão numa proposta institucional, ao invés de somente enfocar os professores que estão trabalhando com alunos com necessidades educacionais especiais. Sobre a resistência dos professores em relação à inclusão, Amaral (1994) afirma que ela se manifesta por meio de preconceitos que criam estereótipos em torno do aluno com deficiência. Estereótipos que, em geral, identificam o aluno com deficiência como retardado, incapaz, coitado ou vítima. Nesse sentido, cabe à escola incorporar a proposta inclusiva, oferecendo um espaço de discussão destinado a todos os envolvidos, quais sejam, pais, professores, funcionários, alunos e sociedade.

\section{Percepção sobre os pais dos alunos com síndrome de Down:}

Os professores comentam que alguns pais são participativos e preocupados com o filho, embora eles percebam que os pais apresentam dificuldades de apostar na capacidade de aprendizagem do filho. Os professores também mencionam que os pais têm dificuldades de incentivar a independência e autonomia e apostar nas potencialidades do filho.

A proposta inclusiva não deve se restringir à escola, desconsiderando o trabalho com a família e a sociedade em geral. Sendo assim, não há como concebermos um trabalho voltado à inclusão, sem que haja uma parceria entre a escola e a família. Autores como Hanson et al. (2001) e Beyer (2005) apontam para essa parceria como importante fator no processo de inclusão. 
Além disso, cabe mencionar que a inclusão se inicia na família, sendo ela responsável pela constituição do laço de filiação, oferecendo ao filho um lugar no contexto familiar. Em geral, o laço de filiação está fragilizado porque, diante das impossibilidades apontadas pelo diagnóstico médico, pais têm dificuldade de apostar nas potencialidades do filho. Nesse sentido, é de fundamental importância o trabalho clínico a ser feito com a criança e seus pais, buscando resgatar o laço de filiação e construir novos desejos e expectativas em relação à criança (OLIVEIRA- MENEGOTTO, 2006). Sendo assim, a família exerce uma função primordial, devendo aliar-se à escola. Ademais, as dificuldades de apostar nas potencialidades do filho e sua capacidade de aprendizagem podem estar associadas ao diagnóstico. Nessa perspectiva, Fabrício, Souza e Zimmermann (2007) afirmam que a inclusão requer um deslizamento da visão centrada na patologia para o foco diferença, uma vez que é reconhecendo as diferenças que podemos apostar nas potencialidades singulares de cada sujeito.

\section{Percepção sobre os pais dos colegas dos alunos com síndrome de Down:}

Os pais, de acordo com a visão dos professores, se dividem entre aqueles que compreendem e defendem a inclusão e aqueles que são resistentes em relação à inclusão.

Os resultados apontam que a inclusão ainda é alvo de críticas por pessoas que entendem que alunos com necessidades educacionais especiais deveriam permanecer segregados em escolas ou classes especiais. Se há necessidade de se falar e discutir sobre inclusão é porque a sociedade ainda está funcionando de uma forma excludente. As falas dos professores, novamente, apontam para a importância de trabalharmos numa proposta inclusiva que envolva não apenas a escola, mas também os familiares e, de forma mais abrangente, a sociedade.

Como a perspectiva da educação inclusiva é um processo que está sendo implantando nas escolas recentemente, vivemos num momento de transição. Nesse sentido, devemos compreender que o tensionamento e a resistência fazem parte do processo (AMARAL, 1994). Por isso, é importante que, além de entendermos a resistência como algo inerente à educação inclusiva, possamos intervir, considerando a escola como um todo, ou seja, considerando, alunos, familiares, funcionários, além dos professores.

\section{Considerações Finais}

O artigo cumpriu com o objetivo de discutir os discursos de professores de 12 escolas da cidade de Novo Hamburgo/RS sobre a inclusão de alunos com síndrome de Down. Os resultados remeteram às reflexões sobre a carência de discussões sobre inclusão nos âmbitos acadêmicos e escolares, levando os professores a uma sensação de desamparo, impotência e incompetência. Isso porque a diferença mobiliza o professor, fazendo brotar resistências e temores. Ela, inevitavelmente, desestabiliza o professor, na medida em que o coloca num lugar de não saber fazer. 
Os resultados também apontaram para a escola como um espaço que deveria amparar os professores em suas angústias e dúvidas, oferecendo não somente recursos materiais, mas garantindo a inclusão a partir de espaços de discussão, reflexão e formação. A escola necessita de um trabalho que leve em consideração todos os agentes que fazem parte da educação: alunos, professores, funcionários, familiares e os mais diversos campos da sociedade.

Ademais, os resultados revelaram a importância de um trabalho interdisciplinar, considerando os especialistas que trabalham clinicamente com os alunos com necessidades educacionais especiais e os professores. Além disso, apontaram para a importância do resgate do sujeito e da diferença, como algo que engendra a aprendizagem.

Em síntese, os professores manifestaram em seus discursos um sentimento de desamparo frente à inclusão e, ao mesmo tempo, um apelo, que deve ser escutado e, na medida do possível, atendido. Trata-se de um apelo, no sentido de acolher a sua angústia e apoiá-lo no processo, por meio de um trabalho interdisciplinar que articule a saúde e a educação. Nesse sentido, a Psicologia Escolar poderá contribuir, juntamente com a Pedagogia, sobretudo, oferecendo um espaço de escuta e acompanhamento ao professor.

\section{REFERENCIAS:}

ALMEIDA-VERDU, A. C. M.; FERNANDES, M. C.; RODRIGUES, O. M. P. R. A inclusão de pessoas com necessidades educativas especiais: implementação de práticas inclusivas e aspectos de planejamento educacional. Interação em Psicologia, Curitiba, v. 6, n. 2, p. 223-231, jul./dez. 2002.

AMARAL, L. A. Pensar a diferença/deficiência. Brasília: Coordenadoria Nacional para Integração da Pessoa Portadora de Deficiência, 1994.

ARAGÃO, L. B. et al. Inclusão de alunos portadores de necessidades especiais em escolas públicas: processo e atuação do psicólogo na escola. Revista do Mestrado em Educação - UFS, São Cristóvão, n. 8, p. 79-88, jan/jun. 2004.

BEYER, H. O. Inclusão e avaliação na escola: de alunos com necessidades educacionais especiais. Porto Alegre: Mediação, 2005.

BRASIL. Constituição (1988). Constituição da República Federativa do Brasil. Brasília, DF: Senado, 1988.

BRASIL. Ministério da Educação e do Desporto - MEC. Lei no 9.394, de 20 de dezembro de 1996. Estabelece as diretrizes e bases da educação nacional. Diário Oficial [da] República Federativa do Brasil, Brasília, 23 dez., 1996.

BRASIL. Saberes e práticas da inclusão: avaliação para identificação das necessidades educacionais especiais. 2. ed. Brasília, MEC/SEESP, 2006. 
BRASIL. Decreto Legislativo $n^{\circ}$. 198 de 13 de junho de 2001. Aprova o texto da Convenção Interamericana para a Eliminação de Todas as Formas de Discriminação contra as Pessoas Portadoras de Deficiência. Brasília, 2001.

BRASIL. Decreto $n^{\circ}$. 3.956 de 08 de outubro de 2001. Promulga a Convenção Interamericana para a Eliminação de Todas as Formas de Discriminação contra as Pessoas Portadoras de Deficiência. Brasília, 2001.

CONGRESSO INTERNACIONAL “SOCIEDADE INCLUSIVA”. Declaração Internacional de Montreal. Montreal, 2001.

FABRÍCIO, N. M. C.; SOUZA, V. C. B.; ZIMMERMANN, V. B. Singularidade na inclusão: estratégias e resultados. São José dos Campos: Pulso, 2007.

GILMORE, L.; CAMPBELL, J.; CUSKELLY, M. Developmental Expectations, Personality Stereotypes and Attitudes Towards Inclusive Education: community and teacher views of Down syndrome. International Journal of Disability, Development and Education, Australia, v. 50, n. 1, p. 65-76, Mar. $2003 \mathrm{a}$.

GILMORE, L.; CAMPBELL, J.; CUSKELLY, M. Changing Student Teachers' Attitudes Toward Disability and Inclusion.JournalofIntellectual \& Developmental Disability. [S.1.], v. 28, n 4, p. 369-379, Dec. 2003 b.

HANSON, M. et al. After Preschool Inclusion: children's educational pathways over the early school years. Council for Exceptional Children. v. 68, n. 1, p. 6583,2001 .

HOLDEN, B.; STEWART, P. The inclusion of students with Down syndrome in New Zealand schools. Down Syndrome News and Update, v. 2, n. 1, p. 24-28, 2002.

REHABILITATION INTERNATIONAL. Carta para o Terceiro Milênio. Londres: Assembléia Governativa da Rehabilitation International, 1999.

KARAGIANNIS, A.; STAINBACK, W.; STAINBACK, S. Fundamentos do ensino inclusivo. In: STAINBACK, S.; STAINBACK, W. (Org.). Inclusão: um guia para educadores. Porto Alegre: ArtMed, 1999. p. 21-34.

LAVILLE, C.; DIONNE, J. A construção do saber: manual de metodologia da pesquisa em ciências humanas. Porto Alegre: Artmed; Belo Horizonte: UFMG, 1999.

MANTOAN, M. T. E. Ser ou estar, eis a questão: explicando o déficit intelectual. Rio de Janeiro: WVA, 2000.

MARTINI, F. O. et al. Você tem síndrome de Down: algumas reflexões sobre a não-comunicação do diagnóstico entre pais e filhos. Prâksis : Revista do ICHLA - Instituto de Ciências Humanas, Letras e Artes, Novo Hamburgo, ano 4, v.2, p. 31-37,jul/dez. 2007. 
MENDES, E. G. A radicalização do debate sobre inclusão escolar no Brasil. Revista Brasileira de Educação, v. 11, n. 33, p. 387-405, set./dez. 2006.

MICHELS, M. H. Gestão, formação docente e inclusão: eixos da reforma educacional brasileira que atribuem contornos à organização escolar. Revista Brasileira Educação, Rio de Janeiro, v. 11, n. 33, p. 406-423, set./dez. 2006.

MRECH, L. M. Educação Inclusiva: realidade ou utopia? Educação on-line, 2001. Disponível em <www.educacaoonline.pro.br >. Acesso em: 6 maio 2008.

MRECH, L. M. Psicanálise e educação: novos operadores de leitura. São Paulo: Pioneira, 1999.

MUKHERJEE, S.; LIGHTFOOT, J.; SLOPER, P. The inclusion of pupils with a chronic health condition in mainstream school: what does it mean for teacher? Educational Research. v. 42, n. 1, p. 59-72, Spring 2000.

OLIVEIRA-MENEGOTTO, L. M. Da filiação à inclusão: uma articulação entre psicanálise e educação. In: . Educação, cultura e trabalho. Novo Hamburgo: Feevale, 2006. p. 89-96.

REHABILITATION INTERNATIONAL. Carta para o Terceiro Milenio. Londres: Assembléia Governativa da Rehabilitation International, 1999.

SAAD, S. N. Preparando o caminho para a inclusão: dissolvendo mitos e preconceitos em relação à pessoa com síndrome de Down. São Paulo: Vetor, 2003.

SANCHES, I.; TEODORO, A. Da integração à inclusão escolar: cruzando perspectivas e conceitos. Revista Lusófona de Educação, Lisboa, n. 8, p. 63-83, jul. 2006.

SILVA, S. C.; ARANHA, M. S. F. Interação entre professora e alunos em salas de aula com proposta pedagógica de educação inclusiva. Revista Brasileira de Educação Especial. Marília, v. 11, n. 3, p. 373-394, set./dez. 2005.

UNESCO. Declaração de Salamanca e linha de ação sobre necessidades educativas especiais. Brasília: CORDE, 1994.

VOIVODIC, M. A. Inclusão escolar de crianças com síndrome de Down. Rio de Janeiro: Vozes, 2007.

Recebido em: novembro de 2008

Aceito em: fevereiro de 2010 